\title{
Regeneration and treatment of sulfidic spent caustic using analytic hierarchy process
}

\author{
Asadollah Karimi ${ }^{1}$, Esmaeil Fatehifar ${ }^{2 *}$, Reza Alizadeh ${ }^{3}$, Iraj Ahadzadeh ${ }^{4}$ \\ ${ }^{1} \mathrm{Ph} . \mathrm{D}$. Student, Environmental Engineering Research Center, Faculty of Chemical Engineering, Sahand University of Technology, \\ Tabriz, Iran \\ ${ }^{2}$ Professor, Environmental Engineering Research Center, Faculty of Chemical Engineering, Sahand University of Technology, \\ Tabriz, Iran \\ ${ }^{3}$ Associate Professor, Environmental Engineering Research Center, Faculty of Chemical Engineering, Sahand University of \\ Technology, Tabriz, Iran \\ ${ }^{4}$ Assiatant Professor, Faculty of Chemistry, Tabriz University, Tabriz, Iran
}

\begin{abstract}
Background: Sulfur compounds must be removed from petroleum because they contribute to environmental pollution. A strong alkaline solution such as caustic soda is used to remove these compounds. This spent caustic has high values for chemical oxygen demand (COD) concentration, $\mathrm{pH}$ and total sulfur. In this study, the regeneration and treatment methodology of sulfidic spent caustic was investigated by applying the analytic hierarchy process (AHP).

Methods: The evaluation index system developed was based on group decision-improved AHP. Expert Choice software was used to simplify decision-making when choosing a practical method and prioritizing treatment of spent caustic. Cost, environmental considerations, availability and scale-up were chosen as criteria and wet air oxidation and biological and catalytic methods were selected as alternative methods. The treatment and regeneration of spent caustic was carried out in a batch bubble column reactor loaded with IVKAZ catalyst and the effluent was treated in a precipitation-stirred tank reactor.

Results: Evaluation indicated that cost ranked first among criteria at $40.9 \%$. The results showed that the proposed process produced about $13 \%$ (wt) of caustic, $50 \mathrm{~g} / \mathrm{L}$ of COD and $36 \mathrm{~g} / \mathrm{L}$ of $\mathrm{S}^{2}$.

Conclusion: The results indicate that the catalytic method was more effective (0.45) than wet air oxidation and the biological method. This process regenerated more than $85 \%$ of initial caustic and the economy of the process improved by the recycling of the stream of caustic.

Keywords: Catalytic oxidation, Wastewater treatment, Recovery, Expert Choice

Citation: Karimi A, Fatehifar E, Alizadeh R, Ahadzadeh I. Regeneration and treatment of sulfidic spent caustic using analytic hierarchy process. Environmental Health Engineering and Management Journal 2016; 3(4): 203-208. doi: 10.15171/EHEM.2016.21.
\end{abstract}

\section{Article History:}

Received: 17 July 2016

Accepted: 19 September 2016

ePublished: 1 October 2016

\section{Introduction}

Industrial wastewater is a major source of pollution in the environment and has negative consequences for human life. Refineries create deleterious waste that must be treated. Caustic scrubbing solutions are commonly used in liquefied petroleum gas units to eliminate impurities and acid constituents such as mercaptans, $\mathrm{H}_{2} \mathrm{~S}$ and $\mathrm{CO}_{2}$. Spent caustic in wastewater is strictly handled and disposed of because it contains high amounts of contaminants. Spent caustic is a hazardous waste that can be classified reactive and highly corrosive because it contains sulfide and has a high $\mathrm{pH}$ value, respectively. Highly odorous spent caustic, usually sulphitics, may contain high levels of sulfide, mercaptan and phenol (1-3). The US Environmental Protection Agency (EPA) under the Resource Conservation and Recovery Act defines spent caustic as hazardous waste (2) and it is a major effluent from oil refineries (4). Table 1 lists the characteristics of spent caustic from liquified petroleum gas.

Conventional disposal methods such as dumping into deep wells or in the ocean are not acceptable solutions to this problem $(3,5)$; this effluent must be treated and handled properly. Treatment of spent caustic can be carried out by either biological, chemical or thermal processes, each of which can be divided into subcategories (1). Treatment methods such as advanced oxygen process, wet air oxyidation (WAO), incineration, and biological or catalytic pathways which can be used separately or in combination are suggested for treatment of organic compounds (such as spent caustic waste) and refractory substances (6-8). Incineration is suitable for handling of effluent having more than $100 \mathrm{~g} / \mathrm{L}$ of chemical oxygen 
Table 1. Charactricties of spent caustic produced from liquefied petroleum gas

\begin{tabular}{ll}
\hline Item & Value \\
\hline $\mathrm{COD}$ & $100-200 \mathrm{~g} / \mathrm{L}$ \\
$\mathrm{S}^{2-}$ & $80-90 \mathrm{~g} / \mathrm{L}$ \\
Mercaptans & $0-30 \mathrm{~g} / \mathrm{L}$ \\
$\mathrm{pH}$ & $12-13.5$ \\
Phenols & $0.002-0.3 \mathrm{~g} / \mathrm{L}$ \\
Specific gravity & 1.1 \\
$\mathrm{NaOH}$ & $4-5 \mathrm{wt} \%$ \\
\hline
\end{tabular}

demand (COD), but this treatment is expensive and produces more hazardous compounds (9). WAO is generally applied under strict operating conditions (10) using either low, medium or high temperature systems (11). The biological method is generally employed after pretreatment and cannot be applied directly or alone (1214). The catalytic treatment is applied to research and industrial waste (15) and can reduced the COD 50\% under mild operating conditions. The main oxidation reactions of spent caustic are $(16,17)$ :

$$
\begin{aligned}
& \mathrm{NaOH}+1 / 2 \mathrm{Na}_{2} \mathrm{~S}_{2} \mathrm{O}_{3}+\mathrm{O} \rightarrow \mathrm{Na}_{2} \mathrm{SO}_{4}+1 / 2 \mathrm{H}_{2} \mathrm{O} \\
& \mathrm{NaSH}+2 \mathrm{O}_{2}+\mathrm{NaOH} \rightarrow \mathrm{Na}_{2} \mathrm{SO}_{4}+\mathrm{H}_{2} \mathrm{O} \\
& \mathrm{NaSH}+2 \mathrm{O}_{2} \rightarrow 1 / 2 \mathrm{Na}_{2} \mathrm{~S}_{2} \mathrm{O}_{3}+1 / 2 \mathrm{H}_{2} \mathrm{O} \\
& 2 \mathrm{RSNa}+1 / 2 \mathrm{O}_{2}+\mathrm{H}_{2} \mathrm{O} \rightarrow \mathrm{RSSR}+2 \mathrm{NaOH}
\end{aligned}
$$

In this study, analytic hierarchy process (AHP) was applied to simplify decision-making when choosing the most practical method from among WAO, biological and catalytic methods. AHP was also used to prioritize treatment and regeneration of spent caustic. Expert Choice software was chosen for evaluation of the three methods and was applied to predict the optimal methods of regeneration and treatment of spent caustic. The regeneration and treatment of spent caustic was developed at bench pilot plant scale. In this system, the spent caustic was oxidized in a heterogeneous batch reactor. The effluent of the first reactor was then precipitated with hydrated lime in the stirred mixed reactor. All experiments were carried out at the Environmental Engineering Research Center of Sahand University of Technology in October 2015. Figure 1 shows a schematic of the steps required.

\section{Methods}

Software preparation

The focus of this study was on spent caustic regeneration.

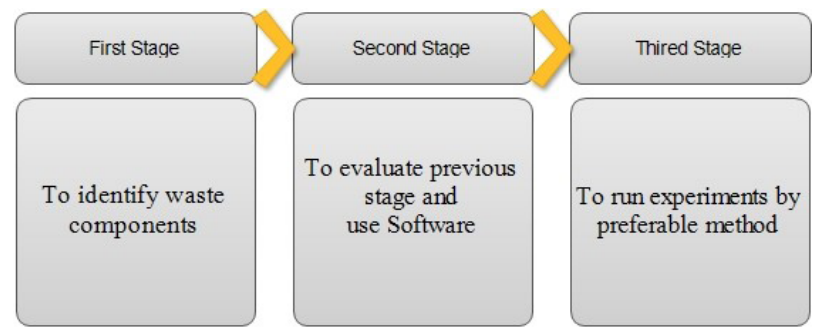

Figure 1. Study steps.
The purpose was to specify the criteria for the intermediate levels and the decision alternatives (18). AHP addresses the influencing criteria and factors that require manual calculation or the use of software. Expert Choice software is easy to use for collaborative decision-making (18) and is the best choice for analyzing data having many variables to fulfill research objectives and limited resources.

The first step in AHP and the software is to develop a hierarchy by breaking the problem down into its components. The main criteria are developed in accordance with the spent caustic regeneration and treatment process. The four criteria selected are cost, environmental impact, availability and scale-up and the three methods selected were WAO, biological and catalyst methods. Figure 2 shows the hierarchy for this analysis. The basic design consists of pairwise criteria and alternatives.

\section{Experimental procedure}

Catalytic oxidation was used to treat and regenerate spent caustic from waste solution provided by a refinery in Iran. Figure 3 is a schematic of the two $500 \mathrm{~mL}$ batch reactors. The oxidation reactor is a bubble column with $40 \mu \mathrm{m}$ pore size. The precipitation stirred tank reactor is a cylindrical glass column with an agitator (Figure 3). The cobalt phthalocyanine catalyst (JSC) was employed to treat and regenerate waste in the first reactor.

The temperature was determined using a $500 \mathrm{~mL}$ (shofballoon of DW2) in the first reactor. A thermocouple was applied to detect the reactor temperature. The second reactor operated at ambient temperature. The system was operated at a constant stirring rate of $50 \mathrm{rpm}$ for 60 minutes. Both reactors operated at atmospheric pressure. Catalytic oxidation reactions (1)-(4) were carried out in the first reactor. All solutions were made with deionized water. Standard thiosulfate titrant, standard iodine titrant, $\mathrm{HCl}$ and indicator were purchased from Merck for titration ( $\mathrm{S}^{2-}$ and alkalinity). $\mathrm{H}_{2} \mathrm{SO}_{4}, \mathrm{Ag}_{2} \mathrm{SO}_{4}$, and $\mathrm{HgSO}_{4}$ were purchased from Merck for $\mathrm{COD}$ determination. $\mathrm{CaCO}_{3}$ was obtained from Carlo Erba for the lime solution. The alkalinity, $\mathrm{pH}, \mathrm{COD}$ and $\mathrm{S}^{2-}$ of the effluent were analyzed using standard methods for the examination of water and wastewater (19). The COD concentration was measured by the dichromate method with a UV-Vis spectrophotometer (Jenway 6705). A pH analyzer (Metrohm) was applied for $\mathrm{pH}$ measurement. Temperature, reaction time and air flow were selected as the independent variables because these parameters contribute to completion of the reaction in the bubble column reactor. Experiments were also carried out

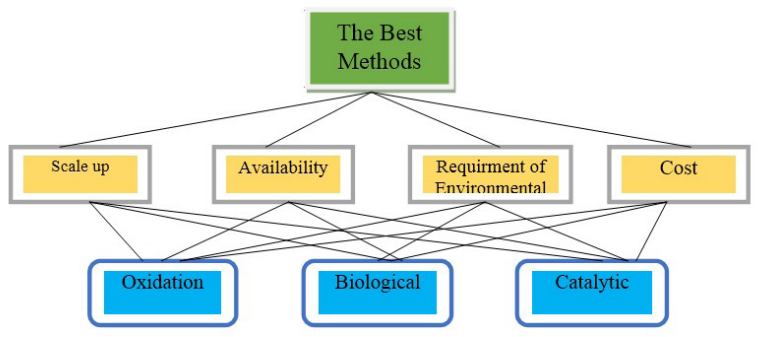

Figure 2. Hierarchy view of criteria and alternatives. 


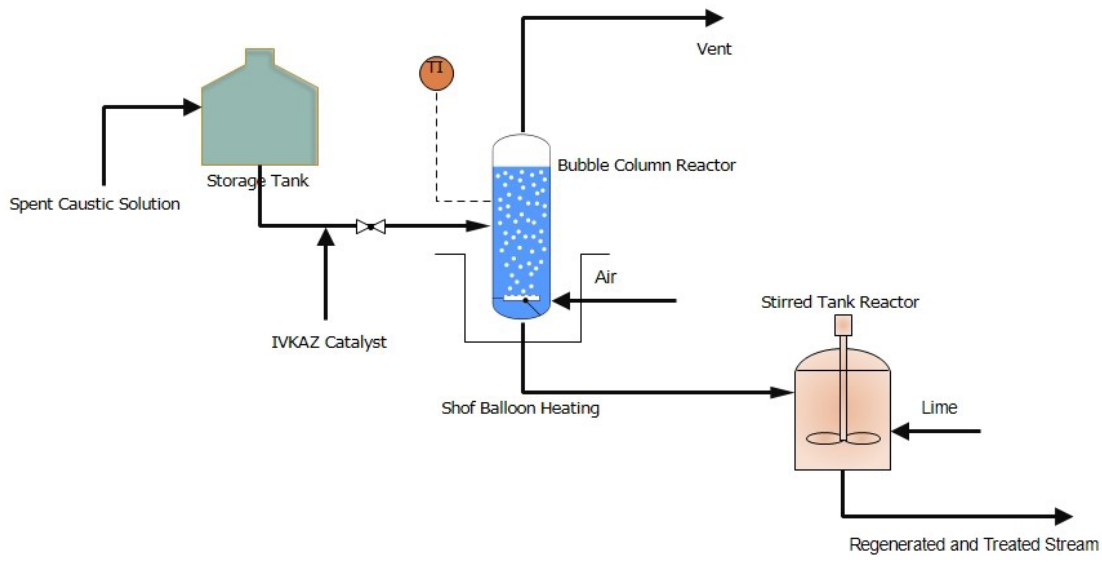

Figure 3. Schematic of bench scale pilot.

to assess temperature, reaction time and air flow. Table 2 lists the independent variables.

\section{Results}

Software results

A pairwise comparison was done based on the results for alternatives and criteria. The questionnaire design used a numerical scale ranging from 1 to 9 as shown in Table 3. The priority and importance of the alternatives and criteria were compared pairwise. Table 4 shows the pairwise comparison matrix of the main criteria.

The results of pairwise comparison are shown in Figure 4. The greatest preference was for cost at $40.9 \%$ and

Table 2. The independent test variables

\begin{tabular}{ll}
\hline Independent variables & Value \\
\hline Temperature $\left({ }^{\circ} \mathrm{C}\right)$ & $80-90$ \\
Reaction time $(\mathrm{min})$ & $20-30$ \\
Air flow $(\mathrm{L} / \mathrm{min})$ & $7-10$ \\
\hline
\end{tabular}

Table 3. Preference qualitative for pair wise comparison method (20)

\begin{tabular}{ll}
\hline Value & Preferences \\
\hline 9 & Extremely preferred \\
7 & Very strongly preferred \\
5 & Strongly preferred \\
3 & Moderately preferred \\
1 & Equally preferred \\
$8,6,4,2$ & - \\
\hline
\end{tabular}

Table 4. Pairwise comparsion matrix

\begin{tabular}{lllll}
\hline & Cost & $\begin{array}{l}\text { Requirement of } \\
\text { environmental }\end{array}$ & Availability & Scale up \\
\hline Cost & 1 & 1 & 4 & 3 \\
$\begin{array}{l}\text { Requirement of } \\
\text { environmental }\end{array}$ & 1 & 3 & 1 \\
Availability & & & 1 & 4 \\
Scale up & & & & 1 \\
\hline
\end{tabular}

Inconsistency: 0.06 environmental impact ranked a strong seond (about 28\%) after cost. Figure 5 shows that the overall inconsistency of these methods as rated by Expert Choice was 5\%.

\section{Experimental results}

$\mathrm{NaOH}$ regeneration is shown in Figure 6 at 80 and $90^{\circ} \mathrm{C}$ for different reaction times at 7 and $10 \mathrm{~L} / \mathrm{min}$ of air flow. Reaction time and temperature influenced the treatment efficiency of catalytic oxidation as evidenced by the improvements seen.

Figure 7 shows the $S^{2-}$ concentration under the same conditions as in Figure 6. An increase in reaction time and temperature allowed reactions 1-4 to be completed, causing the $\mathrm{S}^{2-}$ concentration to decrease. Figure 8 shows that a decrease in $\mathrm{S}^{2-}$ decreased the COD concentration. COD concentration also decreased as the air flow increased at 80 and $90^{\circ} \mathrm{C}$ for $20-30$ minutes of reaction time.

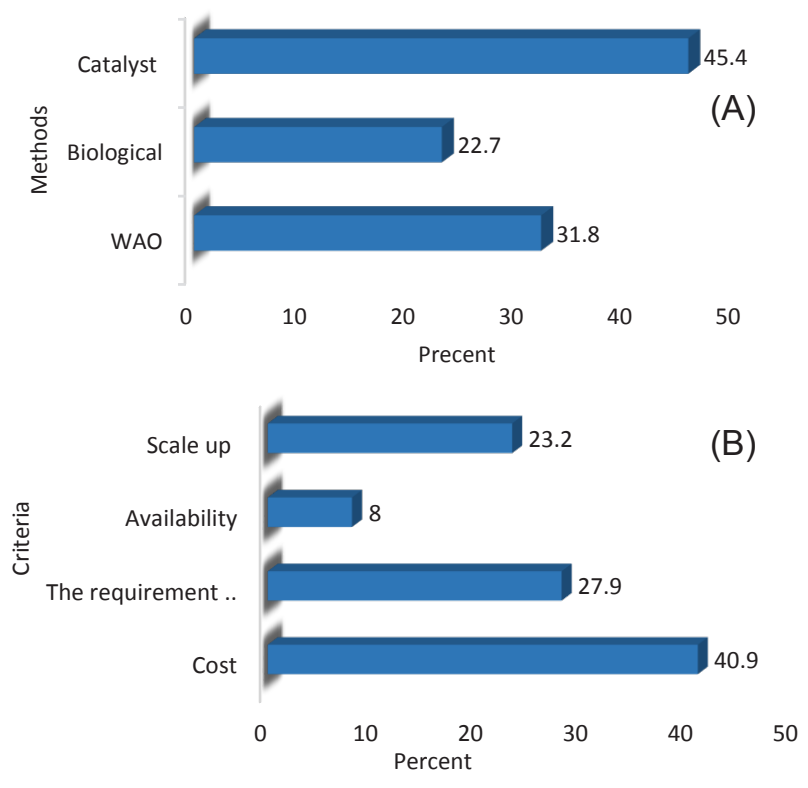

Figure 4. The result of pairwise comparison in expert choice software (A) Alternatives of regeneration (B) Criteria factor. 


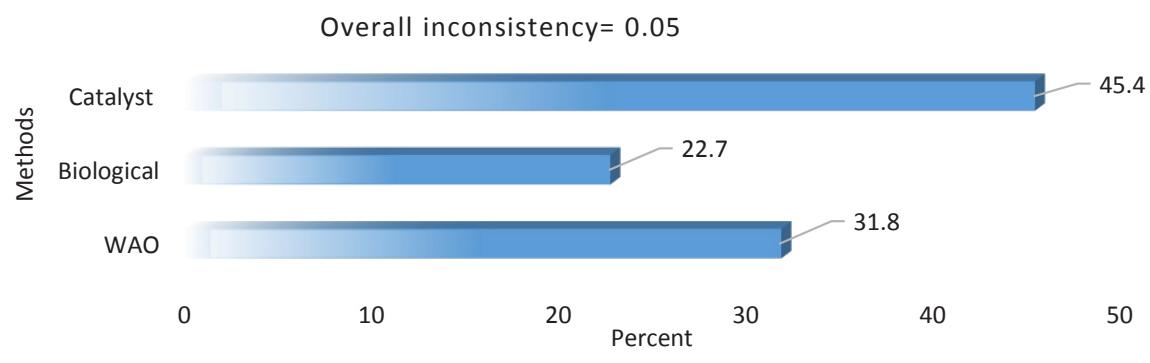

Figure 5. Overall inconsistency result in expert choice software.

\section{Discussion}

\section{Software}

The energy consumption of the WAO method was very high, so this process had a high fixed cost in comparison with the catalytic and biological methods. WAO is generally used as a pretreatment $(8,9)$; therefore, the present method should be used as an auxiliary treatment. Although WAO cannot satisfy environmental requirements alone, it is one way to help alleviate pollutants such as COD and $\mathrm{S}^{2-}$.

The performance of the biological method relates to COD concentration, phenolic components and $\mathrm{pH}$. This method is restricted and could not be applied directly because a high level of COD and phenolic components can cause loss of microorganisms and treatment would cease $(10,20)$. This means that the biological method must be employed through means such as WAO, which increases the total cost of processing.

The catalytic method decreased the COD concentration by $50 \%$ (15) and the operating condition were mild and employed separately. The investment and operational
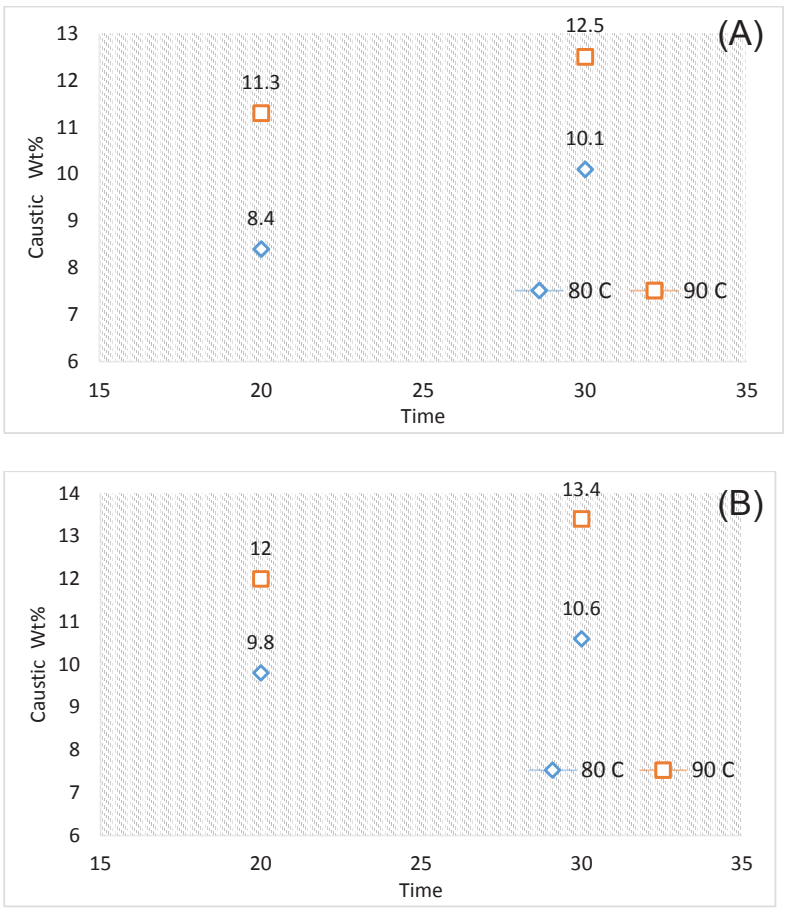

Figure 6. Amount of caustic after regeneration (A) $7 \mathrm{~L} / \mathrm{min}$ and (B) $10 \mathrm{~L} / \mathrm{min}$. costs of the catalytic method was lower than the other methods. Note that catalytic oxidation scales up easily and can be employed without pretreatment (15); thus, it has top priority as an alternative method.

Overall inconsistency is a major area of evaluation of the AHP method. An inconsistency ratio of about $10 \%$ or less is usually considered "acceptable," but particular circumstances may warrant the acceptance of a higher value.

\section{Experimental}

Figure 6 shows that the impact of reaction time was more perceptible. An increase in temperature aided completion of reaction 4 , increasing the percentage of caustic to $13.4 \%$ (wt). Temperature was the most remarkable variable, so the focus was on this factor. The LPG unit used 15\% (wt) caustic for desulfurization of hydrocarbon and 13.4\% (wt) of the caustic could be recycled back to the unit. The recycled stream helped reduce processing costs, which
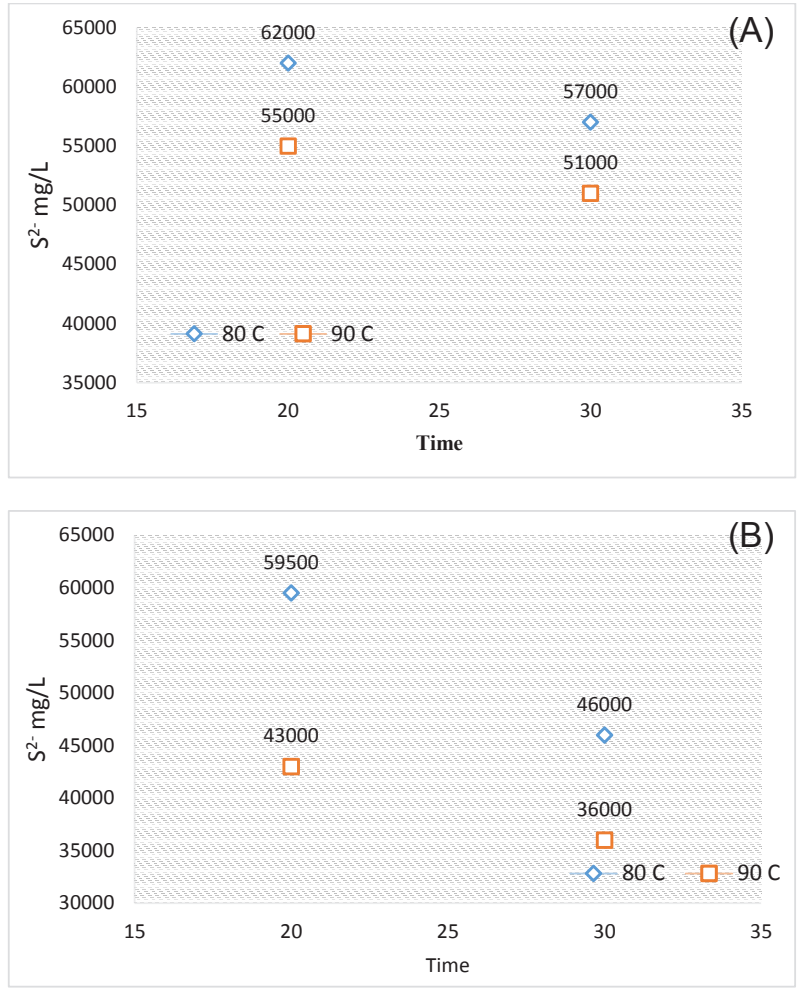

Figure 7. $\mathrm{S}^{2-}$ concentration value (A) $7 \mathrm{~L} / \mathrm{min}$ and (B) $10 \mathrm{~L} / \mathrm{min}$. 


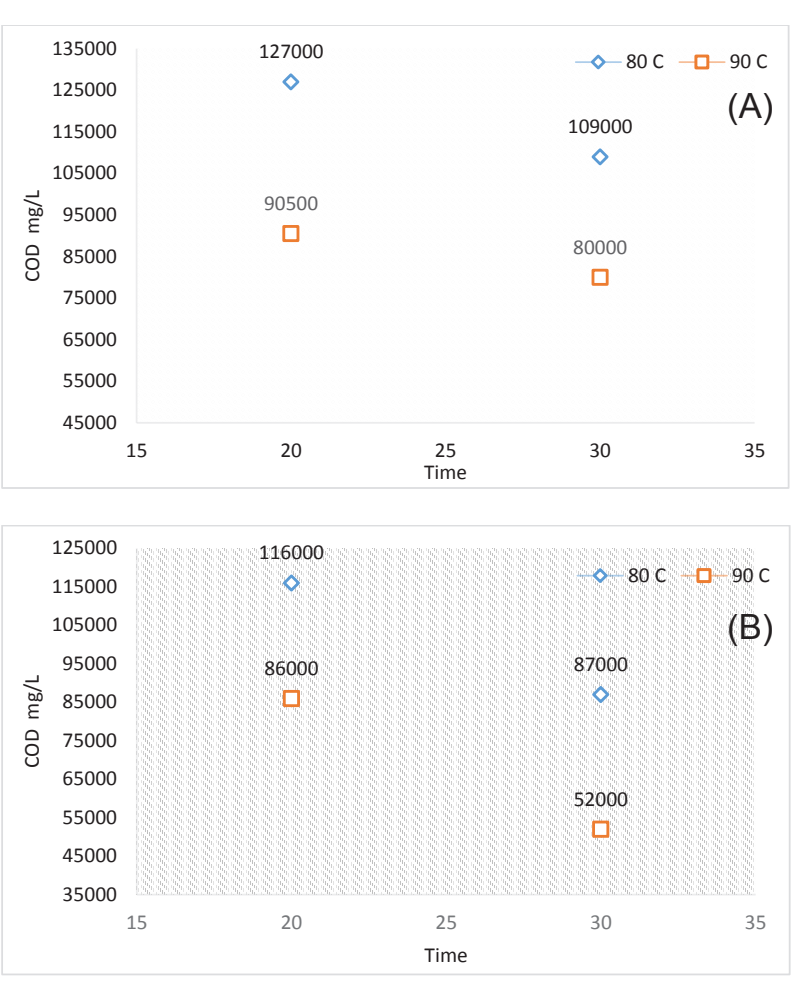

Figure 8. COD concentration value (A) $7 \mathrm{~L} / \mathrm{min}$ and (B) $10 \mathrm{~L} / \mathrm{min}$.

were high. The reaction time was not long and was more favorable than for the WAO, advanced oxidation and biological methods $(2,10,14,22)$.

Figure 7 demonstrated that efficient air flow decreasaed the $\mathrm{S}^{2-}$ concentration because the reactions reach completion in the bubble column reactor. Thiosulfate in alkaline media is a product of the chemical oxidation of sulfide (23-25). As the temperature increased, catalytic oxidation causedmore sulfides to be converted to sulfate and thiosulfate. The sulfate generated in the oxidation reactor occurs according to the precipitation reaction shown in Eq. (5) in the stirred tank reactor with lime. $\mathrm{Na}_{2} \mathrm{SO}_{4}+\mathrm{Ca}(\mathrm{OH})_{2} \rightarrow \mathrm{CaSO}_{4}(\mathrm{~s}) \downarrow+2 \mathrm{NaOH}$ The customary method of eliminating sulfate from wastewater is by the addition of hydrated lime. The precipitation reactor was designed to carry the reaction to completion; thus, sulfate and thiosulfate were generated in the bubble column reactor and reacted with $\mathrm{Ca}(\mathrm{OH})_{2}$. Increased deposition of calcium sulfate occurred in the second reactor, decreasing the $\mathrm{S}^{2-}$ concentration.

Figure 6 shows a decrease in $\mathrm{NaOH}$ recovery from the spent caustic stream were the result of increased production of disulfides. As a result of catalytic oxidation (reactions 1 and 2), COD decreased because the sulfate was completely oxidized. The decline in generation of tiosulfide and sulfate increased the amount of $\mathrm{S}^{2-}$ and COD in Figures 7 and 8, respectively. It was found that increasing the air flow assisted in completion of the reactions. Figures 6-8 show that an increase in oxygen shifted the reaction to the right by eliminating the sulfide ions easily during reactions 20 and 3 .

\section{Conclusion}

This study was divided into 2 parts: the AHP followed by a batch pilot plant study. The goal of AHP was to determine the optimum method for treating spent caustic waste. The preferred method was the catalytic method at $45.4 \%$ and this was selected as the proposed method. After selecting the best method for spent caustic regeneration and treatment, experiments were conducted using catalytic air oxidation in a batch bubble column and a mixed precipitation reactor. The best value for recovery of $\mathrm{NaOH}$ was $13.4 \%$ (wt) for an initial weight of $4 \%$ (wt), which could then be recycled. Reusing this stream improved the system by decreasing the cost of materials and reducing wastewater effluent. The temperature and pressure conditions were mild in this process. The $\mathrm{S}^{2-}$ of the effluent decreased from 81 to $36 \mathrm{~g} / \mathrm{L}$ under the optimal conditions. This decreased the amount of $S^{2-}$ by $45 \%$. This decrease in $\mathrm{S}^{2-}$ decreased the COD in wastewater from 160 to $52 \mathrm{~g} / \mathrm{L}$.

\section{Acknowledgments}

The authors would like to thank the Environmental Engineering Research Center for their cooperation.

\section{Ethical issues}

Ethical issues (plagiarism, informed consent, misconduct, data fabrication and/or falsification, double publication and/or submission redundancy) have been strictly observed by the authors.

\section{Competing interests}

The authors declare that no competing interests exist.

\section{Author contributions}

All authors contributed equally and all authors participated in the data acquisition, analysis, and interpretation.

\section{References}

1. Hawari A, Ramadan H, Abu-Reesh I, Ouederni M. A comparative study of the treatment of ethylene plant spent caustic by neutralization and classical and advanced oxidation. J Environ Manage 2015; 151: 105-12. doi: 10.1016/j.jenvman.2014.12.038.

2. Sheu SH, Weng HS. Treatment of olefin plant spent caustic by combination of neutralization and Fenton reaction. Water Res 2001; 35(8): 2017-21. doi: 10.1016/S00431354(00)00466-8.

3. Ahmad W. Neutralization of Spent Caustic from LPG Plant at Preem AB Goteborg [dissertation]. Goteborg, Sweden: Chalmers University of Technology; 2010.

4. Munirasu S, Haija MA, Banat F. Use of membrane technology for oil field and refinery produced water treatment-A review. Process Saf Environ Prot 2016; 100: 183-202. doi: 10.1016/j.psep.2016.01.010.

5. Grover R, Gomaa HM. Proven technologies manage Olefin plant spent caustic. Hydrocarbon Processing 1993; 72(9): 61-70.

6. Yadav A, Teja AK, Verma N. Removal of phenol from water by catalytic wet air oxidation using carbon bead supported iron nanoparticle containing carbon nanofibers 
in an especially configured reactor. J Environ Chem Eng 2016; 4(2): 1504-13. doi: 10.1016/j.jece.2016.02.021.

7. Golmohammadi S, Ahmadpour M, Mohammadi A, Alinejad A, Mirzaei N, Ghaderpoori M, et al. Removal of blue cat 41 dye from aqueous solutions with $\mathrm{ZnO}$ nanoparticles in combination with US and US- $\mathrm{H}_{2} \mathrm{O}_{2}$ advanced oxidation processes. Environmental Health Engineering and Management Journal 2016; 3(2): 107-13. doi: $\quad$ 10.15171/EHEM.2016.08.

8. Jaafarzadeh Haghighi Fard NA, Jorfi S, Ahmadi M, Mirali S, Kujlu R. Treatment of mature landfill leachate by chemical precipitation and Fenton advanced oxidation process. Environmental Health Engineering and Management Journal 2016; 3(1): 35-40.

9. Debellefontaine H, Chakchouk M, Foussard JN, Tissot D, Striolo P. Treatment of organic aqueous wastes: wet air oxidation and wet peroxide oxidation. Environ Pollut 1996; 92(2): 155-64. doi: 10.1016/0269 7491(95)00100-X.

10. AlNaizy R. Economic analysis for wet oxidation processes for the treatment of mixed refinery spent caustic. Environ Prog Sustain Energy 2008; 27(3): 295-301. doi: 10.1002/ ep.10261.

11. Zhu W, Bin Y, Li Z, Jiang Z, Yin T. Application of catalytic wet air oxidation for the treatment of $\mathrm{H}$-acid manufacturing process wastewater. Water Res 2002; 36(8): 1947-54. doi: 10.1016/S0043-1354(01)00419-5.

12. Conner JA, Beitle RR, Duncan K, Kolhatkar R, Sublette $\mathrm{KL}$. Biotreatment of refinery spent-sulfidic caustic using an enrichment culture immobilized in a novel support matrix. Appl Biochem Biotechnol 2000; 84-86: 707-19.

13. de Graaff M, Bijmans MF, Abbas B, Euverink GJ, Muyzer G, Janssen AJ. Biological treatment of refinery spent caustics under halo-alkaline conditions. Bioresour Technol 2011; 102(15): 7257-64. doi: 10.1016/j.biortech.2011.04.095.

14. Oh SY, Shin DS. Removal of total dissolved solids in spent caustic using biochar: pretreatment for subsequent biological treatment. Clean Soil Air Water 2015; 43(1):
92-5. doi: 10.1002/clen.201300784.

15. UOP LLC. http://www.uop.com. Accessed August 1, 2007.

16. Mohammadbeigi K, Tajerian M. Demercaptanization of Distillate (DMD). Petroleum \& Coal 2004; 46(1): 17-22.

17. Matthews R. Performance update: low pressure wet air oxidation unit at Grangemouth, Scotland. Environ Prog Sustain Energy 1997; 16(1): 9-12. doi: 10.1002/ ep.3300160113.

18. Ramanathan, R. A note on the use of the analytic hierarchy process for environmental impact assessment. J Environ Manage 2001; 63(1): 27-35. doi: 10.1006/jema.2001.0455.

19. Eaton AD, Clesceri LS, Rice EW. Standard Methods for the Examination of Water and Wastewater. 21st ed. Washington DC: American Public Health Association; 2005.

20. Ghodsipur SH. Multiple objective decision making (MODM). Tehran: Amirkabir University Press; 2006. [In Persian].

21. Najaf Poor AA, Dousti S, Joneidi Jafari A, Hosseinzadeh A. Efficiency in phenol removal from aqueous solutions of pomegranate peel ash as a natural adsorbent. Environmental Health Engineering and Management Journal 2016; 3(1): 41-6.

22. Czimer B, Kovács A, Petró J. Treatment of Spent Merox Caustic Waste in Industrial Ecology Frames. Period Polytech Chem Eng 2015; 59(3): 215-20. doi: 10.3311/ PPch.7601.

23. Millano EF, Sorber CA. Treatment of thiosulfate-containing wastewater in activated sludge systems. J Water Pollut Control Fed 1986; 58(9): 917-923.

24. Karimi A, Fatehifar E, Alizadeh R, Ahadzadeh I. Regeneration of Spent Caustic of Olefin Unit in a Bubble Column Reactor: Treatment and Recovery Optimization. Environ Prog Sustain Energy 2016. doi: 10.1002/ep.12433.

25. Rolia E, Chakrabarti CL. Kinetics of decomposition of tetrathionate, trithionate, and thiosulfate in alkaline media. Environ Sci Technol 1982; 16(2): 852-7. doi: 10.1021/ es00106a006. 